\title{
White Paper: Pathways to Progress in Newborn Screening for Sickle Cell Disease in Sub-Saharan Africa
}

Lewis Hsu ${ }^{1^{*}}$, Obiageli E. Nnodu ${ }^{2,3}$, Biobele J. Brown ${ }^{4}$, Furahini Tluway ${ }^{5}$, Shonda King ${ }^{6}$, Livingstone G. Dogara ${ }^{7}$, Crystal Patil ${ }^{8}$, Sergey S. Shevkoplyas ${ }^{9}$ Guillaume Lettre ${ }^{10}$, Richard S. Cooper ${ }^{11}$, Victor R. Gordeuk ${ }^{12}$ and Bamidele O. Tayo ${ }^{11}$, on behalf of the Africa Sickle Cell Research Network (AfroSickleNet)

${ }^{1}$ Division of Pediatric Hematology-Oncology, Department of Pediatrics, University of Illinois at Chicago, Chicago, IL, USA

${ }^{2}$ Department of Hematology and Blood Transfusion, University of Abuja, Abuja, Nigeria

${ }^{3}$ Centre of Excellence for Sickle Cell Disease Research \& Training, University of Abuja, Abuja, Nigeria

${ }^{4}$ Department of Pediatrics, College of Medicine, University of Ibadan, Ibadan, Nigeria

${ }^{5}$ Sickle Cell Program, Department of Hematology and Blood Transfusion, Muhimbili University of Health and Allied Sciences, Dares Salaam, Tanzania

${ }^{6}$ Department of Health Social Work, University of Illinois Hospital and Health Sciences Systems, Chicago, IL, USA

${ }^{7}$ Department of Hematology and Blood Transfusion, Ahmadu Bello University Teaching Hospital, Zaria, Nigeria

${ }^{8}$ Department of Women, Children and Family Health Science, University of Illinois at Chicago, College of Nursing, Chicago, IL, USA

${ }^{9}$ Department of Biomedical Engineering, University of Houston, Houston, TX

${ }^{10}$ Montreal Heart Institute, Montréal, QC H1T 1C8, Canada

${ }^{11}$ Department of Public Health Sciences, Loyola University Chicago Stritch School of Medicine, Maywood, IL, USA

${ }^{12}$ Division of Hematology and Oncology, Department of Medicine, University of Illinois at Chicago, Chicago, IL, USA

“Corresponding author: Lewis Hsu, Division of Pediatric Hematology-Oncology, Department of Pediatrics, University of Illinois at Chicago, Chicago, IL, USA, Tel: (312) 996-6143; E-mail: lewhsu@uic.edu

Received date: April 23, 2018; Accepted date: June 22, 2018; Published date: July10, 2018

Copyright: ( $2018 \mathrm{Hsu} \mathrm{L}$, et al. This is an open-access article distributed under the terms of the Creative Commons Attribution License; which permits unrestricted use; distribution; and reproduction in any medium; provided the original author and source are credited.

\begin{abstract}
Sickle Cell Disease (SCD) is among the most common single-gene diseases in the world but evidence-based comprehensive health care has not been implemented where the highest prevalence of SCD occurs, in sub-Saharan Africa (SSA). It represents an urgent health burden, both in terms of mortality and morbidity with an estimated mortality of $8-16 \%$ in children under 5 years in SSA. Addressing the high mortality of SCD in SSA and for effective management of SCD, newborn screening (NBS) should be incorporated with prevention of infections (including pneumococcal septicaemia and malaria), parental education and support at all levels of healthcare provision to enable timely recognition. The NBS working group of the Africa Sickle Cell Research Network (AfroSickleNet) collaboration surveyed current projects in NBS in SSA, and current conditions that hinder more widespread implementation of NBS for SCD. Solutions based on new point-of-care testing technology to disseminate education, and implementation science approaches that leverage existing resources are proposed.
\end{abstract}

Keywords: Sickle cell disease; Newborn screening; Hemoglobin

\section{Introduction}

Sickle cell disease (SCD) is an inherited disorder of the hemoglobin and it is the most common, clinically significant, genetic disease in Africa, especially sub-Saharan Africa (SSA). Over 700 variants have been identified out of which 2 ( $\mathrm{HbS}, \mathrm{HbC}$ ) have high frequency in Africa [1]. The variants are characterized by presence of sickled hemoglobin. The sickled hemoglobin results from a point mutation resulting in a change from GAG to GTG thus leading to the substitution of Glutamic acid by valine that occurs at position 6 of the $\beta$-globin chain. This substitution leads to formation of insoluble polymers of hemoglobin, disturbance in red blood cell (RBC) membrane and the eventual formation of 'sickle'-shaped RBC. This substitution is the hallmark of the disease [1,2]. It is a multi-system disorder affecting almost every organ of the body $[1,3]$. There are 4 chromosomal haplotypes - Benin, Senegal, Bantu (CAR) and ArabIndia $[1,2,4]$. It is obvious that most of the Classical Haplotypes are of African origin however the true burden of the disease in Africa still not known $[1,5]$. The African Union in 2005, World Health Organization
(WHO) in 2007 and the United Nation's General Assembly (UNGA) in 2009 declared SCD a public health problem that requires control [3]. Globally, an estimated 465,000 babies are born annually with significant disorders of hemoglobin ( $\mathrm{Hb})$; of these, 401,000 are with SCD [6] and 70\%-75\% are in sub-Saharan Africa (SSA) [1,3,4]. About 150,000 babies are born yearly with SCD in Nigeria and it is estimated that by the year 2050 this figure will increase by $100 \%$ in the absence of effective and sustainable control strategies [6,7].

These conditions have significant global, economic and social impact affecting not only patients but their families and the community at large $[3,8]$. The burden of SCD is high in Africa with especially high mortality amongst the under-fives $[1-3,6,7,9]$ being the 6 th leading cause of death in children under 5 years in Nigeria [7]. It is worthy of note that $70 \%$ of deaths in SCD are preventable [10]. The high prevalence of SCD in Africa and unacceptable morbidity and mortality levels are worsened by lack of or inadequate control programs, dearth of basic facilities to manage patients, absence of systemic screening for SCD and secondary prevention. These are also undermined by poor research, documentation, and intervention protocols. All these culminate in annual loss of several millions of 
disability adjusted years [1]. SCD in the developed world accounts for only $10 \%$ of the SCD patient population and life expectancy is high among SCD patients [3] while review of some of African countries shows that it is $1 \%-2 \%$ in North Africa, $1 \%$ in South Africa, Cameroun, Republic of Congo, Gabon, Ghana and Nigeria 20\%-30\%, Uganda $45 \%$ $[8,11]$ where the homozygous Sickle cell anemia accounts for $16.2 \%$ of all pediatric death [11]. In Dar-es-salaam Tanzania hospital based cohort studies shows mortality in under-fives to be $7.3 \%$ [10]. SCD affects 20-25 million globally [3] with 150,000-300,000 individuals born every year in Africa with SCD [12], but despite this high figure it is still lagging behind Hemophilia, cystic fibrosis and other genetic disorders in having a comprehensive team care [13]. The burden of the disease is still rising in Africa because of lack of proper comprehensive control plan. The bane of care for subjects with SCD in Africa hinge on the fact that in many African countries there are few or virtually no facilities for appropriate diagnosis and management, data about frequency, clinical course, morbidity and mortality are also limited $[1-3,8-10]$ as well as record of birth and all deliveries is still a challenging aspect of data management in Africa [3]. Without these, it is difficult to convince African governments and donor agencies to commit on a comprehensive care and management plan despite its public health importance $[1,10]$.

Effective management of SCD revolves round genetic counselling, neonatal screening and early diagnosis $[1,3,10,14]$. This will help improve the quality of care and management of SCD by instituting early measures as is noted among the high resource countries where mortality from SCD dropped from $3 \%$ to $0.13 \%$ per 100 person years of observation in US and UK $[1,3,6,10]$. The best modalities for care for SCD include pre-natal diagnosis, new born screening, Bone Marrow transplant, Penicillin prophylaxis and genetic counselling [1]. Primary prevention, through a well-coordinated program involving a multidisciplinary team of caregivers is central to effective management of SCD. This will entail the provision of early diagnosis, genetic counseling and screening. Such standard neonatal SCD control programs will lead to early introduction of the SCD subject into comprehensive care programs. Newborn screening (NBS) is relatively new in Africa with few pilot studies conducted in some countries; Ghana, Burkina Faso, Benin, Congo and Nigeria [1-3,7,14,15]. Although NBS is yet to become routine because of cost and the absence of well-functioning health insurance schemes to defray the cost from the family and relations $[3,8,15]$, the good news is that WHO intends to support primary prevention of SCD in Africa because evidence for its benefit is overwhelming [4,8]. However various governments need to demonstrate interest in having viable and comprehensive care plans on ground without which success will be slow and challenging. For the success of such a program in Africa, nutrition and nutrition education need to be integrated. Additionally, policies on genetic counseling and screening need to be legislated and given the necessary executive wherewithal to be implemented. Governments should have effective national SCD control programs and public awareness on the usefulness and benefit of primary prevention should be strengthened [3]. Greater international partnerships and cooperation is advocated to facilitate access to education, management, surveillance and treatment of SCD $[3,8]$. Simple and representative and affordable approach in generating acceptable data on SCD mortality in children so as to convince policy makers in Africa to institute primary care is to test blood already collected for some other studies like HIV, Malaria, malnutrition etc. [2]. The survival of these approaches are well within the framework of national program for prevention of Noncommunicable diseases
(NCDs) [8]. Lastly, monitoring and evaluation must be integral parts of any program on SCD. In conclusion, screening of SCD is a longawaited program which has lofty goals in the control of this condition and mitigating its effects on the economy and society.

\section{Sickle cell screening efforts in Southern Africa}

South Africa has in place Policy Guidelines of 2001, for the Management and Prevention of Genetic Disorders including SCD; however the implementation of genetic testing has remained in the tertiary urban facilities and academic institution where patients have to pay for these services [16]. This situation has been attributed to priority being given to communicable diseases such as HIV/AIDS and TB [17]. This phenomenon is true for most SSA countries.

There have been other pilot NBS for SCD projects in Angola where over 36000 newborns were screened and were given best possible care between 2011 and 2013 [18]. In published conference proceedings, Malawi presented a proposal for a pilot SCD NBS, the outcomes of which have not been published. These initiatives have not translated into sustainable national wide NBS programs. Most countries both developed and developing are facing different challenges during implementation of NBS activities. However, SSA countries face additional set of challenges including prioritizing public health interventions in the face of budgetary constraints and double burden of disease. SSA also has unique and diverse social and cultural aspects that need special considerations [19-22]

\section{Perspectives on screening for sickle cell - alternative strategies and technologies}

The WHO Regional Office for Africa has recommended the need for developing national SCD control programs that include advocacy, prevention and counselling, early detection, treatment, surveillance, research, and community education and partnerships as the way forward [23]. SSA can begin to implement these recommendations in place of the following strategies which have been successful in Asia, Pacific and the Middle East and North Africa countries.

There is a need for developing national SCD NBS policy and protocol that are locally appropriate and acceptable taking into consideration available resources. This process needs local champions who have sufficient technical knowledge and experience to guide relevant stakeholder to reach a consensus. The local champions must be able to involve and obtain support from the Ministry of health to ensure successful implementation and expansion of the program. This process goes hand in hand with public engagement and advocacy in order to garner community support which is critical [24]. There is also a need to use UN treaties and conversions on the rights of the child of which most countries are signatories, to convince policy makers to include SCD NBS in their plans aiming at reducing childhood mortality. The UN Convention on the Rights of the Child, article 24(1) [25] for instance, requires signatories to "recognize the right of the child to the enjoyment of the highest attainable standard of health" and to take measures to "diminish infant and child mortality".

Public private partnerships (PPP) have been successful in supporting some activities like laboratory needs and advocacy. Leveraging NGO strengths and utilizing existing capacity in academic institutions (training and support policy and protocol development) have been shown to improve success in implementation of NBS, in addition to the benefits obtained from existing government efforts $[18,24,26]$. Sustainability of established SCD NBS hinges on formal 
Page 3 of 9

recognition, institutionalization and integration into the public health system (Child monitoring cards to include NBS) along with immunization schedule and advocating for NBS to be covered by health insurance schemes [24]. Mobile phone short messages (SMS) have been found useful in communicating with and follow up of affected families [26].

\section{Objectives}

The objectives were to identify countries in West Africa that had implemented newborn screening for sickle cell disease and describe their programs in terms of test facilities, outcomes of testing and availability of follow-up care for children diagnosed to have sickle cell care.

\section{Methodology}

This was a review of published scientific literature on newborn screening for Sickle cell disease in West Africa. Literature search was performed on PubMed / MEDLINE, African Journals Online (AJOL) and Cochrane databases for all articles using search strings or key words such as sickle cell, haemoglobinopathies, newborn screening, neonatal screening and West Africa. Only original studies published in peer reviewed scientific journals were included. Studies in which initial testing was done after the neonatal period were excluded. Variables analysed included the city/country of study, health facilities in which testing took place, number of newborn screened and the percentage with sickle cell disease. Other variables included site of enrollment of neonates and follow-up care plans. Where documented, challenges were also noted.

\section{Results}

Six publications that met the inclusion criteria were found and covered reports from six countries namely Nigeria, Ghana, Liberia, Senegal, Republic of Benin and Burkina Faso [14,27-31] (Table 1). None of the studies covered the entire country but each was limited to certain cities of the country.

\section{High performance liquid chromatography (HPLC)}

Acceptability: Data on acceptability of neonatal screening was available from only two studies from Benin and Nigeria with acceptability rate of $99.7 \%$ and that from Liberia with a rate of $99.0 \%$ $[27,28]$. These indicate that implementation of universal newborn screening for SCD is likely to be acceptable within the continent even though the countries reported here are few.

Sampling and testing: Source of blood sampling was mostly by heel prick; cord blood was used in one study (Table 1) the screening test used in all studies was Isoelectric focusing (IFE). IEF and HPLC are the main techniques used for newborn screening. However, laboratories in sub-Saharan Africa may encounter challenges using a fully automated system such as HPLC. In addition, IEF offers some advantages in Africa such as less need for regular maintenance of the instrument and delivery of kits and the possibility of producing IEF agarose gels locally at a reduced cost [32,33]. This favours its widespread use in Africa as first line.

\begin{tabular}{|c|c|c|c|c|c|c|c|}
\hline $\begin{array}{l}\text { Year } \\
\text { publication }\end{array}$ & Country (city) & Duration & $\begin{array}{l}\text { No. } \\
\text { Babies }\end{array}$ & $\begin{array}{l}\text { SCD frequency } \\
(\%)\end{array}$ & Test & Type of sampling & $\begin{array}{l}\text { Sample } \\
\text { type }\end{array}$ \\
\hline 2008 & Nigeria (Benin) & 3 months & 644 & $3.0 \%$ & $\begin{array}{l}\text { Isoelectric } \\
\text { focusing } \\
\text { confirmed with } \\
\text { citrate agar }\end{array}$ & Systematic & $\begin{array}{l}\text { Heel prick on } \\
\text { filter paper }\end{array}$ \\
\hline 2016 & Liberia (Monrovia) & 13 months & 2785 & $1.2 \%$ & IEF & Systematic & $\begin{array}{l}\text { Heel prick on } \\
\text { filter paper }\end{array}$ \\
\hline 2009 & $\begin{array}{ll}\begin{array}{l}\text { Burkina } \\
\text { (Ouagadougou) }\end{array} & \text { Faso }\end{array}$ & 4 years & 2341 & $1.8 \%$ & $\begin{array}{l}\text { IEF confirmed } \\
\text { with HPLC }\end{array}$ & Systematic/targeted & $\begin{array}{l}\text { Cord blood/ } \\
\text { filter paper }\end{array}$ \\
\hline 2008 & Ghana (Kumasi) & Over 10 years & 202244 & $1.9 \%$ & IEF & Systematic & Not stated \\
\hline 2009 & Republic of Benin & 3 years & 1189 & & IEF & Targeted & $\begin{array}{l}\text { Heel prick on } \\
\text { filter paper }\end{array}$ \\
\hline 2003 & Senegal (Dakar) & & 478 & $2.1 \%$ & $\begin{array}{l}\text { IEF Confirmed } \\
\text { with citrate agar }\end{array}$ & Systematic & $\begin{array}{l}\text { Dried blood } \\
\text { spots }\end{array}$ \\
\hline
\end{tabular}

Table 1: Neonatal Screening for sickle cell disease (SCD) in Africa: countries, techniques and frequencies of SCD.

For sustainability of a neonatal screening program, it is important that the technology for laboratory diagnosis be available within the confines of the country. In most of the countries in this review, this was the case. However, in the study based in Nigeria, diagnostic test was performed in the Republic of Benin while the Liberia based study had its specimen analyzed in Ghana [27,28]. Although this highlights the potential value of a south-south partnership in establishing a newborn screening program, it also indicates inability of the countries in sustaining the program by themselves under prevailing circumstances. The number of babies screened in the studies ranged from 478 to
202244 (Table 1). Duration of the studies or programs ranged from 3 months in those from Nigeria to more than 10 years in that from Ghana $[14,27]$ (Table 1 ). The reports were mostly pilot studies and only the program in Ghana seems to be established and ongoing. It was started in 1993 as a demonstration project in Kumasi Ghana by the Comprehensive Sickle Cell Center at the Children's hospital in Philadelphia in collaboration with the Ministry of Health and other institutions in Ghana [14]. Screening of neonates in a country may be applied to either at risk populations or to all babies [32]. All but two studies in this review screened all neonates systematically, the 
exception being that by Rahimy et al. [29] in the Republic of Benin who targeted at risk mothers and another by Kafando et al. [30] in Burkina Faso whose study was in two stages: the first used systematic sampling and the second was targeted on infants of carrier couples or families who already had SCD children. In the study by Rahimy et al. pregnant women were tested before 28 weeks and carriers of $\mathrm{Hb} \mathrm{C}$ or S counselled, sensitized on the need for neonatal testing and their neonates were tested within 8 weeks. This two-step process has the advantage of making mothers aware of sickle cell disorders and sensitizing them on the need for prenatal diagnosis and screening their neonates. However, it may not work in many African settings where mothers book for antenatal care in one health facility but are delivered in a different health facility. Another potential setback of targeted testing is that it cannot yield a true population-based incidence of the disorder.

Prevalence: Prevalence of sickle cell phenotypes in the countries reviewed ranged from $1.2 \%$ in Liberia to $3.0 \%$ in Benin, Nigeria as shown in Table $1[27,28]$. The frequencies reported from studies based on targeted screening such as that of the Republic of Benin [29] need to be interpreted with caution since they would not represent the true frequency of the disorder in the general population.

Sites of enrollment and follow-up care: Most neonates were enrolled from maternity hospitals in the Nigeria and Burkina Faso, in a medical center in Liberia $[27,28,34]$. In Ghana, babies were enrolled both at birth and at well infant visits [14]. The advantages or challenges of each site of enrollment were however not highlighted. Given the peculiarities of African countries such as a high rate of delivery outside orthodox maternity centers, it will be useful to assess the best sites for capture of neonates in order to cover as high a proportion of newborns as possible [35]

Following diagnosis of sickle cell disease, a few centers enrolled the children into comprehensive sickle cell disease programs [14,29] whilst others referred the children to teaching hospitals, pediatricians or physicians $[27,28]$. In order to benefit maximally from neonatal screening programs, there is need for establishment of comprehensive care programs to be directly linked to the screening programs in order to implement preventive and therapeutic interventions that would improve survival of affected children. In the study by Rahimy et al. [29], cases were enrolled into a Comprehensive sickle cell program and after 8040 patient years of follow up, mortality rate was 15.5/1000 which was ten times lower than the general mortality rate of under 5 children in Benin Republic.

Cost effectiveness: There has been no cost effectiveness study of newborn screening for SCD in West Africa. This is necessary to guide health care financing and appropriate allocation of funds for health care.

\section{Comparing Low- and High-resource Contexts (uniqueness / differences) of NSB}

Resource constraints and positive features in African efforts to screen for sickle cell disease: Universal newborn screening for SCD has successfully been implemented in countries with low prevalence of SCD compared to SSA countries which have $85 \%$ of the global burden of SCD. African countries also have a disproportionate burden of infectious diseases and malnutrition. Although SCD is a $100 \%$ preventable genetic non-communicable disease which had been described over 100 years ago, it was only in 2008 that the WHO declared it a public health problem followed by recognition by the
WHO Afro Region in 2010 as a major NCD in the continent $[2,36,37]$. With low ratio of trained health workers to the population, low resource allocation to health in national budgets, many disease control efforts in Africa are dependent on international donor funding which go primarily to areas identified as country priorities. However, in setting priorities, the government of SSA countries have not recognized the complex relationship between sickle cell disease, infectious diseases and other NCDs. This is in part due to paucity of epidemiologic data on the natural history of SCD in Africa with the use of extrapolated data from studies done in Europe and America which have different environmental and social backgrounds and the absence of sustained effective lobby for continent wide implementation of evidence-based interventions for its control.

SCD manifests in affected individuals early in life and progresses with periods of relative good health punctuated by catastrophic illness and bone pains. Its presentation in individuals vary but in general, individuals with SCD have altered immunity and are more susceptible to infections such that more than $50 \%$ of children born with SCD will die before their fifth birthday and $90 \%$ before attaining adulthood if poorly managed in childhood. As such, SCD is contributing to under five and maternal mortality [36]. Individuals with SCD suffer complications such as heart disease, stroke, hypertension, renal failure and others with increasing age and almost every organ system in the body is affected thus fuelling other NCDs such as cardiovascular and chronic kidney diseases. However, when individuals with SCD are identified early and given infection prophylaxis, optimal nutrition and hydration, screened for risk of stroke and placed on hydroxyurea, the morbidity and mortality is reduced. This is the main reason for newborn screening to identify individuals with SCD early enough to apply these lifesaving interventions.

Newborn screening for SCD involves the collection of a drop of blood from a baby in the first few days after birth and testing that blood sample for abnormal hemoglobin before symptoms of SCD manifest. Blood collected by capillary heel prick is applied to circles on a filter paper, allowed to dry and shipped to the laboratory for screening by isoelectric focusing or HPLC. Positive samples are confirmed by an alternate testing method before the result is communicated to the baby's parents. Babies identified to have SCD are entered into a register and commenced on infection prophylaxis, other interventions and follow up. Newborn screening for SCD requires a functional public health system with equipment reagents and consumables for screening and confirmatory testing (diagnosis). Genetic counsellors, nurses, clinicians and other health care workers are required to offer basic health maintenance and comprehensive care. Effective communication and transportation systems as well as financing are essential for sustainability. Currently, many African countries (except Egypt) have no national newborn screening program. Pilot screening programs have been carried out in Ghana, Benin, Burkina Faso, DR Congo, Gabon, Uganda, Mali, and Tanzania for several years and need to be up scaled nationally. Nigeria has laid the infrastructure for a national program which is hampered by funding, high cost of reagents, skilled personnel and inertia in sustained sample collection. WHO African Region member states resolved to raise awareness, improve disease prevention and early detection, set up effective clinical, laboratory and imaging facilities and screen newborns for SCD reached in 2008 [37,38]. However, despite these commitments, universal newborn screening in African nations is yet to be achieved hence the need for alternative SCD screening strategies which is feasible, affordable and practical within the framework of existing health systems in the continent. 
Page 5 of 9

Africa's crude birth rate is 38.3 per 1000 with $54 \%$ antenatal coverage and births attended by skilled health personnel compared to 96\% attendance in the United States and 99\% in Europe. Implementing newborn screening as it is currently practiced in Europe and the Americas requires various categories of health care workers which will be difficult to achieve with the continent's 1.4 million shortfall in skilled health workers [39]. Alternative strategies for newborn screening for SCD include leveraging on expenditure on immunization services, integration into existing well developed infectious disease programs as has been done in Uganda with the use of dried blood spots from the prevention of maternal to child transmission of HIV program, the training of HIV /AIDS programs counsellors to offer genetic counselling in SCD, the use of point of care devices by community health extension and other front line health care workers to offer screening in primary health care within immunization programs and well as the deployment of mobile technology for follow up and service delivery.

Cost is a major impediment for implementation of newborn screening for SCD as a new vertical program. Careful deployment of current resources with integration into existing public health programs such as immunization and HIV AIDS programs will go a long way to establish early detection of SCD across Africa.

\section{Perspective on Screening}

Some public health experts have taken the position that newborn screening diagnosis is justified when effective medical care can be offered. Resource limitations in many areas of Africa do not make effective medical care for SCD. However, NBS diagnosis could be useful even if only a minimal intervent in is possible (e.g. folic acid, antimalarial, education, genetic counselling). Firstly, knowing the SCD diagnosis could change the response of the family to that child's pain or fevers. Secondly, a couple that has produced a child with SCD can be offered targeted screening and counselled about the risks of additional children with SCD. In other words, part of the value of NBS is social change, even if there is not much medical care available for the child.

Peer-to-peer support groups in social media, linking adolescents from the U.S. and U.K. with peers / groups in Africa, sharing stories of coping with symptoms and everyday life with SCD (needs to be curated to make sure medical information is true and correctly interpreted).

In addition to NBS, alternative screening strategies for SCD might be implemented in Africa
(1) Screen pregnant women - Detecting that a pregnant woman has SCD might permit more careful management, to try to reduce the 8fold perinatal mortality $[40,41]$. Detecting that a mother has sickle cell trait could lead to targeted testing of the spouse and the newborn, as well as genetic counselling. In most of the African continent, termination of pregnancies is not culturally accepted or legal, so the genetic counselling would need to be very culturally-sensitive counselling about risks.

(2) Screen adolescents in school - SCD testing can be conducted in conjunction with classroom discussion. Sickle cell trait and SCD can be diagnosed, and genetic counselling offered before entering the reproductive years. The classroom context can be adolescent reproductive health programs which already exist in most settings (tap into UNICEF initiatives involving child health), or health topics that are loosely related (e.g. Tanzania has also school-based deworming programs education about parasitic worms and their role in anemia could also mention that SCD is an anemia with a different etiology than worms).

(3) Family clusters could be screened for SCD - When families come together to medical centers, they could all be tested for SCD. One strategy could be to dovetail the SCD testing with the timing of immunizations (e.g. screening test drawn at the time for one immunization, and counselling positives at 6 weeks vaccination visits).

Technologic solutions could answer current logistic challenges of NBS- Hemoglobin analysis could require supplies that do not tolerate high temperature and humidity during transport, supplies with a short shelf life, cost of diagnostic tests, biohazard disposal of used tests, sustainability of government funding, health worker shortages, language barriers, telecommunication, public health records (how to archive positives, could inform government spending and help advocate for more support from international donors).

Screening efforts will benefit greatly from sickle cell diagnosis by point-of-care test that requires little training, instead of the current HPLC or electrophoresis technology that require equipment and trained personnel. The test would need to be validated under conditions relevant for use in Africa: low cost, durable storage, and ability to diagnose sickle hemoglobin plus hemoglobin $\mathrm{C}$ and beta thalassemia trait. Several organizations are developing point-of-care tests - the ones known to the authors from public information such as NIH Small Business grants are in Table 2.

\begin{tabular}{|c|c|c|}
\hline & Test principle & References \\
\hline Halcyon & Paper chromatography & {$[52]$} \\
\hline Rockland Immunochemicals & $\begin{array}{l}\text { hemoglobin isoform-specific antibodies in a lateral } \\
\text { flow chamber }\end{array}$ & $\begin{array}{l}\text { http://www.genengnews.com/gen-news-highlights/rockland-wins-sbir-grant- } \\
\text { for-sickle-cell-disease-poc-device/81250315/ }\end{array}$ \\
\hline CORRELIA BIOSYSTEMS & $\begin{array}{l}\text { sandwich immunoassay format on a next generation } \\
\text { lateral flow test platform }\end{array}$ & [53] \\
\hline Daktari Diagnostics & $\begin{array}{l}\text { small, battery-operated centrifuge to separate sickle } \\
\text { cells from normal red blood cells, based on } \\
\text { differences in their cell density. The isolated sickle } \\
\text { cells fraction is then detected by a simple optical } \\
\text { reader inside the Daktari instrument. }\end{array}$ & {$[54]$} \\
\hline
\end{tabular}




\begin{tabular}{|l|l|l|}
\hline Capnia Inc & $\begin{array}{l}\text { Detect Elevated end-tidal carbon monoxide (ETCO) } \\
\text { as a measure of hemolysis, with a simple, rapid, } \\
\text { noninvasive breath test }\end{array}$ & {$[55]$} \\
\hline DxDiscovery & Immunoassay in lateral-flow platform & \\
\hline
\end{tabular}

Table 2: List of point-of-care tests.

Implementation Science to pull out the relevant lessons from different experience: Newborn screening for SCD has demonstrated many benefits in multiple studies, and may be regarded as an Evidence-Based Intervention (EBI) because of the efficacy of early prevention of infection [42]. However, as described above, newborn screening has not been implemented widely in the nations with high incidence of SCD. How can the challenges of complex organizations, multiple stakeholders, and variable standards of care be overcome to implement newborn screening in Africa?

Introducing NBS clearly entails complex processes, and multiple levels of community issues and stakeholder needs. Achieving NBS outcomes at each site is maximized by paying attention to the factors that positively affect the quality of the implementation and the fit of the intervention to the local context. Implementation Science could help organizations achieve outcomes by taking accountability for implementing EBIs in their particular setting [43]. With a rich array of techniques and theories for implementing interventions [44], Implementation Science can help clarify which lessons to learn from existing NBS efforts in USA, Europe, and Brazil, and which aspects are not applicable to sub-Saharan Africa. For example, the Implementation Science Getting-To-Outcomes (GTO) method can help to (a) guide assessment of needs and resources across patient, community and health care organization levels, and (b) guide the implementation, evaluation and sustainability of screening.

Empowerment evaluation (EE) provides a comprehensive planning, implementation, and evaluation strategy. Putting the logic and tools of evaluation into the hands of practitioners and consumers can help achieve a results-based approach to accountability in their own specific settings. Ten principles guide empowerment evaluation: improvement, inclusion, democratic participation, social justice, capacity building, organizational learning, community knowledge, community ownership, evidence-based strategies, and accountability. The providers and patients use the logic and tools of evaluation for planning more systematically, implementing with quality, selfevaluating, and using the information for continuous quality improvement, to achieve their desired outcomes [45]. Instead of the traditional approach to bringing in evaluators at the end of a program, the stakeholders use evaluation strategies to guide implementation from the start of the program. Building stakeholder empowerment, the role of evaluator includes the building of local capacity and provision of support to stakeholders at all levels to ask and answer the accountability questions.

An implementation approach can also help align the interests at multiple system levels to work in an accountable way. Comparison of the answers across levels helps identify areas of interdependency between levels, allowing for the kinds of collaboration and communication that are needed for successful implementation with quality. For example, conversation between the national and the regional level stakeholders prior to implementation will help in the development of a strategy rather than running out of resources later and negatively impacting the quality of the implementation. All of these steps will occur through an iterative, collaborative process involving diverse stakeholder groups. GTO will help facilitate the communication and planning across sectors and assist in coordinating the dynamic stakeholder group across systems. GTO may also be used by funders to incorporate quality implementation of EBIs in grant proposals, and one of the authors has success in a SCD grant with this approach [46]. The SCD team perceived the GTO approach as more structured, and with a greater emphasis on stakeholder alignment, compared to previous Improvement Science efforts in sickle cell [47] (Table 3).

Empowerment evaluation might find opportunities for NBS for sickle cell to align with other public health efforts. For example, a sickle cell screening test might be bundled with adult screening tests for other conditions relevant in the African context (e.g. prenatal or premarital screening of women) and newborn screening initially targeted to the babies born to women with sickle cell trait. For another example, counselling about sickle cell trait might be integrated with existing infrastructure for counselling (e.g. HIV, immunizations, nutrition, and breast cancer). Connecting the contribution of SCD to the rate of under-five deaths from malaria [6] and to 8-fold higher maternal perinatal mortality $[40,41]$ could bring enhanced attention to sickle cell screening from the infrastructures built to address those conditions. NBS follow-up programs could have synergy with registries for genomics studies in projects like H3Africa. Messages about NBS could be crafted with the help of the arts/design community, and the help of the music and film for dissemination.

Attributable deaths are hidden because odds ratios estimate mortality attributable to SCD for sepsis, malaria, TB, diarrhoea incidence are same, but fatalities are higher for SCD. It is possible to estimate the potential relative reduction in infectious mortality if the SCD patients are detected and treated as high-risk people. Immunizations are universal but prophylactic antibacterial or antimalarial is not and diagnosis is late and misses the opportunity for malaria prophylaxis and penicillin prophylaxis.

\begin{tabular}{|l|l|l|}
\hline Goal & Sickle Cell connections & Potential Strategy \\
\hline $\begin{array}{l}\text { Reduce mortality in children under } 5 \\
\text { years from infectious disease }\end{array}$ & $\begin{array}{l}\text { Children with SCD have increased bacteremia from } \\
\text { pneumococcus and other bacteria [48,49], increased mortality }\end{array}$ & $\begin{array}{l}\text { Separate the statistics for under-5y mortality and infection } \\
\text { with and other high-risk children, attainable by universal }\end{array}$ \\
\hline
\end{tabular}




\begin{tabular}{|c|c|c|}
\hline & $\begin{array}{l}\text { from malaria, probably increased mortality from diarrheal } \\
\text { disease. } \\
\text { If the population with SCD rises but receives inadequate care to } \\
\text { prevent and treat infections, this subgroup could skew the } \\
\text { infectious disease statistics [6]. } \\
\text { Sickle trait is well-known to improve resistance to malaria, and } \\
\text { might improve resistance to bacteremia [50]. }\end{array}$ & $\begin{array}{l}\text { screening of sick children for SCD. This improves the quality } \\
\text { of the statistics to understand what improvements occur for } \\
\text { the general population, for sickle trait, and what might be } \\
\text { addressed by care for SCD. } \\
\text { Train community health workers to ask whether sick child has } \\
\text { been screened for SCD. }\end{array}$ \\
\hline Reduce maternal perinatal mortality & $\begin{array}{l}\text { Pregnancy in women with } S C D \text { is associated with increased } \\
\text { risks of adverse perinatal and maternal outcomes in both low- } \\
\text { and high-income countries. Meta-analyses show Hazard ratio for } \\
\text { SCD maternal mortality can be } 5.98 \text { to } 10.91 \text { [ } 41,51] \text {. } \\
\text { If the population with SCD rises but is not managed as high-risk } \\
\text { Ob, this subgroup could skew the maternal and perinatal } \\
\text { statistics. }\end{array}$ & $\begin{array}{l}\text { Separate the statistics for women with } S C D \text { and other high- } \\
\text { risk Ob, attainable by universal screening of pregnant women } \\
\text { for SCD. } \\
\text { This improves the quality of the statistics to understand what } \\
\text { improvements occur for the general population and what } \\
\text { might be addressed by care for SCD. } \\
\text { Train community health workers to ask whether pregnant } \\
\text { woman has been screened for SCD. }\end{array}$ \\
\hline sexually-transmitted & $\begin{array}{l}\text { Inherited disease incidence is related to knowledge of inherited } \\
\text { traits before reproduction. (This needs to be phrased carefully) } \\
\text { Prevention programs for HIV and other STD have trained } \\
\text { counselors and reach people of reproductive age. }\end{array}$ & $\begin{array}{l}\text { During counseling for prevention of HIV and other STD, } \\
\text { insert module of information about sickle trait and culturally- } \\
\text { appropriate choices. Offer sickle cell screening for } \\
\text { adolescents so that they are aware of sickle trait status and } \\
\text { can make culturally-appropriate reproductive choices. } \\
\text { Reduces the stigma of the counseling and broadens the } \\
\text { relevance of the counseling to include people with no STD. } \\
\text { Maybe offer testing for sickle trait when providing medical } \\
\text { care for STD. }\end{array}$ \\
\hline $\begin{array}{l}\text { Improve surgical morbidity and } \\
\text { mortality }\end{array}$ & $\begin{array}{l}\text { SCD is associated with increased peri-operative morbidity and } \\
\text { mortality }\end{array}$ & $\begin{array}{l}\text { Separate the statistics for surgical procedures on people with } \\
\text { SCD and other high-risk conditions, attainable by universal } \\
\text { screening of pre-op patients for SCD. } \\
\text { This improves the quality of the statistics to understand what } \\
\text { improvements occur for the general population and what } \\
\text { might be addressed by care for SCD. }\end{array}$ \\
\hline Improve research infrastructure & $\begin{array}{l}\text { Sickle hemoglobin is one of the most common genetic traits in } \\
\text { Africa, and influences multiple hematologic parameters as well } \\
\text { as cardiovascular, renal, pulmonary, nutrition \& growth, } \\
\text { neurologic, psychosocial systems. }\end{array}$ & $\begin{array}{l}\text { Introduce studies of sickle trait and SCD as research foci. } \\
\text { This increases the relevance of research for the general } \\
\text { population. }\end{array}$ \\
\hline
\end{tabular}

Table 3: Examples of alignment.

\section{Future}

Adapt successful/efficacious programs from other health conditions for genetic counseling, especially for adolescents. Funding NBS program will primarily be a public health responsibility of government. However, start-up could be funded by short-term external grants. Unconventional funding might also be used. For example, Tom's Shoes has a philanthropic model for healthcare (a small part of co-pay for a doctor visit in US funds screening and treatment in Africa). Technologic breakthroughs with low-cost point-of-care testing could dramatically reduce costs of equipment and make the costs of NBS attainable for a low-resource country. Forty-year projections by Piel et al. [6] make it clear that SCD can create enormous burdens of healthcare cost and excess mortality. A functional NBS program coupled with preventive care and counselling has the potential to reduce healthcare costs, reduce mortality, and improve workforce productivity.

\section{Scientific/modern medical and traditional medical care for Sickle Cell Disease: Implications for social work intervention}

Globally, there are barriers of difficult access to doctors and nurses with expertise in SCD, and long waits to see them after arrival, which some have called "burdens of treatment" (NIH - Meeting Unmet
Needs, 2002). For people with SCD in Low and Middle-Income Countries (LMIC), these barriers often lead people to utilize the traditional medical system which is care given at the community level by family and/or "trained" community members. Patients with SCD thus have the choice of utilizing two coexisting health systems: (1) the scientific/modern medical care system which includes clinics, hospitals, and health centers, and (2) the traditional medical system which is care given at the community level by family and/or "trained" community members. An example of how patients do not rely exclusively on one system but rather shuttle between the two for their care needs is provided below.

A total of 106 women and 25 traditional birth attendants (TBA's) were interviewed in Nsawam in southeast Ghana, using local community health nurses as interpreters to translate English to $\mathrm{Ga}$ or Twe as needed. The women shuttled between the two health care systems with none of the women reported relying exclusively on one system. Although $65.5 \%$ of the women delivered in hospitals, $45.6 \%$ reported they would have preferred to deliver at home with a TBA or midwife. The women preferred seeing the doctor for their initial antenatal visit and delivery, but most reported seeking health care advice from a TBA. An unexpected finding was the postnatal follow-up patterns: $88 \%$ of women who were referred by local TBA's to the district hospital for more specialized care did return for follow-up, not 
Page 8 of 9

for themselves, but to bring the child in for their first immunization. After this, women returned to the TBA for most primary care for themselves and their child.

Women were interviewed using a twenty-five-item bilingual questionnaire that elicited information about their access and extent of antenatal care, previous births and birth outcome, and postnatal care (Table 4). Initial contacts with the women were made at local clinics in Djankrom and Zongo and the district hospital. The TBA's were interviewed using a nine-item questionnaire that asked questions about their level and extent of training, years of practice, understanding of antenatal care, and referral process.

\begin{tabular}{|c|c|c|}
\hline & Mean & Range \\
\hline \multicolumn{3}{|l|}{ Women } \\
\hline Age & 27.9 & $18-45$ \\
\hline Education (years) & 6.5 & $1-16$ \\
\hline Number of pregnancies & 2.3 & $1-9$ \\
\hline Number of children & 2.1 & $1-7$ \\
\hline Antenatal Care Began (months) & 3.6 & $0-8$ \\
\hline \multicolumn{3}{|l|}{ Traditional Birth Attendants } \\
\hline Age (years) & 61.5 & $28-95$ \\
\hline Years of training & 22.5 & $5-46$ \\
\hline
\end{tabular}

Table 4: Demographic characteristics of women and traditional birth attendants in Nsawam, Ghana (1995).

Building on these findings about follow-up with antenatal and postdelivery women using both modern and traditional medical systems, suggestions can be made for NBS for sickle cell. Because social workers have multidisciplinary training, they can play a valuable role in helping to coordinate care and follow-up efforts with women and children and especially those with SCD. For the purpose of follow-up with sickle cell patients and making sure that parents aware of the child's diagnosis and subsequent care needed, the social work roles of coordinator and liaison are especially needed. A social worker would need to be staffed at the district hospital or health posts located in the rural areas. In this practice area, social workers could not only provide much needed casework the families, but also act as a liaison between the TBA's (who often follow their patients from the villages to the hospital) and the professional staff. As coordinator at the district hospital, social workers can help patients navigate between the two systems of care to maximize health outcomes, while alerting other team members of families who may need more monitoring or education.

\section{Concluding Comments}

This article has described the challenges and opportunities for NBS for SCD, and why this EBI has not been adopted in Africa. Knowledge of EBIs is insufficient for reaching outcomes at scale in a complex world. We described why it is important to look at the African context of each setting for implementation and why it is important for those accountable for implementation to be strategic in planning for implementation to ensure that the EBI achieves outcomes for their setting. Implementation of a successful program for NBS for SCD therefore must be a multilevel process involving communities, families, health system administrators and health care providers. Each of these stakeholder groups needs to understand the barriers to achieving outcomes from its own perspective and context, and this knowledge will help to anticipate implementation issues rather than reacting to them. A newborn screening program for SCD, integrated with preventive care and reproductive counseling, has the potential to reduce healthcare costs, reduce mortality, and improve workforce productivity.

\section{Acknowledgement}

The working meeting of the Africa Sickle Cell Research Network (AfroSickleNet) titled "Team Science to Advance Sickle Cell Research in Africa" was supported by funding provided by the Doris Duke Charitable Foundation Grant \#2015192.

\section{References}

1. Makani J, Ofori-Acquah SF, Nnodu O, Wonkam A, Ohene-Frempong K (2013) Sickle cell disease: New opportunities and challenges in Africa. The Scientific World Journal 2013: 16.

2. Grosse SD, Odame I, Atrash HK, Amendah DD, Piel FB, et al. (2011) Sickle cell disease in Africa: A neglected cause of early childhood mortality. Am J Prev Med 41: S398-405.

3. Mulumba LL, Wilson L (2015) Sickle cell disease among children in Africa: An integrative literature review and global recommendations. IJANS 3: 56-64.

4. Makani J, Williams TN, Marsh K (2007) Sickle cell disease in Africa: Burden and research priorities. Ann Trop Med Parasitol 101: 3-14.

5. Hanchard N, Elzein A, Trafford C, Rockett K, Pinder M, et al. (2007) Classical sickle beta-globin haplotypes exhibit a high degree of long-range haplotype similarity in African and Afro-Caribbean populations. BMC Genet 8: 52.

6. Piel FB, Hay SI, Gupta S, Weatherall DJ, Williams TN (2013) Global burden of sickle cell anaemia in children under five, 2010-2050: Modelling based on demographics, excess mortality, and interventions. PLoS Med 10: e1001484.

7. Baba PI, Yvonne D, Juliana OL, John D, Matthews CE, et al. (2015) Sickle cell disease screening in Northern Nigeria: The co-existence of bthalassemia inheritance. Pediatrics \& Therapeutics 5: 1-4.

8. Schmets G, Rajan D, Organization WH, Kadandale S (2017) Strategizing national health in the 21st century: A Handbook: World Health Organization.

9. Ndeezi G, Kiyaga C, Hernandez AG, Munube D, Howard TA, et al. (2016) Burden of sickle cell trait and disease in the Uganda Sickle Surveillance Study (US3): A cross-sectional study. Lancet Glob Health 4: e195-200.

10. Makani J, Cox SE, Soka D, Komba AN, Oruo J, et al. (2011) Mortality in sickle cell anemia in Africa: a prospective cohort study in Tanzania. PloS one 6: e14699.

11. Okwi AL, Byarugaba W, Ndugwa CM, Parkes A, Ocaido M, et al. (2010) An up-date on the prevalence of sickle cell trait in Eastern and Western Uganda. BMC Blood Disord 10: 5.

12. Diallo DA (2008) [Sickle cell disease in Africa: Current situation and strategies for improving the quality and duration of survival]. Bull Acad Natl Med 192: 1361-1372.

13. Control CfD (2013) Prevention: Sickle cell disease (SCD): data and statistics.

14. Ohene-Frempong K, Oduro J, Tetteh H, Nkrumah F (2008) Screening newborns for sickle cell disease in Ghana. Pediatrics 121: S120-S121.

15. Dennis-Antwi JA, Dyson S, Frempong KO (2008) Healthcare provision for sickle cell disease in Ghana: challenges for the African context. Diversity \& Equality in Health and Care 5: 241-254.

16. Kromberg JG, Sizer EB, Christianson AL (2013) Genetic services and testing in South Africa. J Community Genet 4: 413-423. 
17. Mayosi BM, Flisher AJ, Lalloo UG, Sitas F, Tollman SM, et al. (2009) The burden of non-communicable diseases in South Africa. Lancet 374: 934-947.

18. McGann PT, Ferris MG, Ramamurthy U, Santos B, de Oliveira V, et al. (2013) A prospective newborn screening and treatment program for sickle cell anemia in Luanda, Angola. American journal of hematology 88: 984-989.

19. Padilla CD, Therrell BL (2007) Newborn screening in the Asia Pacific region. J Inherit Metab Dis 30: 490-506.

20. Padilla CD (2008) Towards universal newborn screening in developing countries: Obstacles and the way forward. Ann Acad Med Singapore 37: 6-4.

21. Krotoski D, Namaste S, Raouf RK, El Nekhely I, Hindi-Alexander M, et al.(2009) Conference report: Second conference of the Middle East and North Africa newborn screening initiative: Partnerships for sustainable newborn screening infrastructure and research opportunities. Genet Med 11: 663-668.

22. Saadallah AA, Rashed MS (2007) Newborn screening: Experiences in the Middle East and North Africa. J Inherit Metab Dis 30: 482-489.

23. World Health Organization Regional Office for Africa (2016) Sickle cell disease prevention and control, WHO.

24. Padilla CD, Krotoski D, Therrell BL, Jr. (2010) Newborn screening progress in developing countries--overcoming internal barriers. Semin Perinatol 34: 145-155.

25. Fleitas CJ (1998) The United Nations Convention on the Rights of the Child. Loy Poverty LJ 4: 291.

26. Hettiarachchi M, Amarasena S (2014) Indicators of newborn screening for congenital hypothyroidism in Sri Lanka: Program challenges and way forward. BMC Health Serv Res 14: 385.

27. Odunvbun ME, Okolo AA, Rahimy CM (2008) Newborn screening for sickle cell disease in a Nigerian hospital. Public Health 122: 1111-1116.

28. Tubman VN, Marshall R, Jallah W, Guo D, Ma C, et al. (2016) Newborn Screening for Sickle Cell Disease in Liberia: A pilot study. Pediatric blood \& cancer 63: 671-676.

29. Rahimy MC, Gangbo A, Ahouignan G, Alihonou E (2009) Newborn screening for sickle cell disease in the Republic of Benin. J Clin Pathol 62: 46-48.

30. Kafando E, Nacoulma E, Ouattara Y, Ayeroue J, Cotton F, et al. (2009) Neonatal haemoglobinopathy screening in Burkina Faso. J Clin Pathol 62: 39-41.

31. Mbodj M, Ndoye O, Diarra M, Mbaye BN, Sow TH, et al. (2003) [Sickle cell disease neonatal screening. First evaluation]. Dakar Med 48: 202-205.

32. Tshilolo L, Kafando E, Sawadogo M, Cotton F, Vertongen F, et al. (2008) Neonatal screening and clinical care programmes for sickle cell disorders in sub-Saharan Africa: Lessons from pilot studies. Public Health 122: 933-941.

33. Hajer S, Neila T, Sondess HF, Fekria O, Nabila A, et al. (2012) A lowercost protocol for sickle cell disease neonatal screening in Tunisia. Ann Saudi Med 32: 49-52.

34. Kafando E, Sawadogo M, Cotton F, Vertongen F, Gulbis B (2005) Neonatal screening for sickle cell disorders in Ouagadougou, Burkina Faso: A pilot study. J Med Screen 12: 112-114.

35. Nakua EK, Sevugu JT, Dzomeku VM, Otupiri E, Lipkovich HR, et al. (2015) Home birth without skilled attendants despite millennium villages project intervention in Ghana: Insight from a survey of women's perceptions of skilled obstetric care. BMC Pregnancy Childbirth 15: 243.

36. Modell B, Darlison M (2008) Global epidemiology of haemoglobin disorders and derived service indicators. Bull World Health Organ 86: 480-487.
37. Regional Committee for Africa: Sickle-Cell Disease: a strategy for the WHO African Region, WHO.

38. WHO (2010) Sickle cell disease: A strategy for the WHO African Region. Malabo, Equitarial Giunea: WHO.

39. WHO (2016) Atlas of african health statistics 2016: Health situation analysis of the African Region. Regional Office for Africa, WHO.

40. Asare EV, Olayemi E, Boafor T, Dei-Adomakoh Y, Mensah E, et al. (2017) Implementation of multidisciplinary care reduces maternal mortality in women with sickle cell disease living in low-resource setting. American J Hematolo 92: 872-878.

41. Boafor TK, Olayemi E, Galadanci N, Hayfron-Benjamin C, DeiAdomakoh Y, et al. (2016) Pregnancy outcomes in women with sickle-cell disease in low and high income countries: a systematic review and metaanalysis. Int J Obst Gynaecol 123: 691-698.

42. Gaston MH, Verter JI, Woods G, Pegelow C, Kelleher J, et al (1986) Prophylaxis with oral penicillin in children with sickle cell anemia. A randomized trial. N Engl J Med 314: 1593-1599.

43. Lobb R, Colditz GA (2013) Implementation science and its application to population health. Annu Rev Pub Heal 34: 235-251.

44. Nilsen P (2015) Making sense of implementation theories, models and frameworks. Implement Sci 10: 53.

45. Fetterman DM, Wandersman A (2005) Empowerment evaluation principles in practice. Guilford Press.

46. Wandersman A, Alia K, Cook BS, Hsu LL, Ramaswamy R (2016) Evidence-based interventions are necessary but not sufficient for achieving outcomes in each setting in a complex world: Empowerment evaluation, Getting To Outcomes, and demonstrating accountability. Amer J Eval 37: 544-561.

47. Oyeku SO, Wang CJ, Scoville R, Vanderkruik R, Clermont E, et al. (2012) Hemoglobinopathy Learning Collaborative: using quality improvement (QI) to achieve equity in health care quality, coordination, and outcomes for sickle cell disease. J Heal Care Poor Unders 23: 34-48.

48. Brent AJ, Ahmed I, Ndiritu M, Lewa P, Ngetsa C, et al. (2006) Incidence of clinically significant bacteraemia in children who present to hospital in Kenya: community-based observational study. Lancet 367: 482-488.

49. Ndir A, Diop A, Faye PM, Cisse MF, Ndoye B, et al. (2016) Epidemiology and Burden of Bloodstream Infections Caused by Extended-Spectrum Beta-Lactamase Producing Enterobacteriaceae in a Pediatric Hospital in Senegal. PLOS ONE 11: e0143729.

50. Scott JA, Berkley JA, Mwangi I, Ochola L, Uyoga S, et al. (2011) Relation between falciparum malaria and bacteraemia in Kenyan children: a population-based, case-control study and a longitudinal study. Lancet 378: 1316-1323.

51. Oteng-Ntim E, Meeks D, Seed PT, Webster L, Howard J, et al. (2015) Adverse maternal and perinatal outcomes in pregnant women with sickle cell disease: systematic review and meta-analysis. Blood, 125: 3316-3325.

52. Piety NZ, Yang X, Kanter J, Vignes SM, George A, et al. (2016) Validation of a Low-Cost Paper-Based Screening Test for Sickle Cell Anemia. PLOS ONE 11: e0144901.

53. Boemer F, Vanbellinghen JF, Bours V, Schoos R (2006) Screening for sickle cell disease on dried blood: a new approach evaluated on 27,000 Belgian newborns. J Med Screen 13: 132-136.

54. Kumar AA, Chunda-Liyoka C, Hennek JW, Mantina H, Lee SY, et al (2014) Evaluation of a density-based rapid diagnostic test for sickle cell disease in a clinical setting in Zambia. PLOS ONE 9: e114540.

55. Lal A, Patterson L, Goldrich A, Marsh A (2015) Point-of-care end-tidal carbon monoxide reflects severity of hemolysis in sickle cell anemia. Pediatric blood \& cancer 62: 912-914. 